\title{
Exergy Analysis of Air-source Heat Pump Water Heater
}

\author{
MI Bingjie ${ }^{1, a}$, LUO Qinghai ${ }^{2, b}$ and CHEN Guojie \\ ${ }^{1,2,3}$ School of Urban Construction, University of South China, Hengyang 421001, China \\ Ambj0310@163.com, bluoqinghai001@163.com, 410563871@qq.com
}

\begin{abstract}
Keywords: air source heat pump ; water heater system ; exergy efficiency ; exergy loss coefficient Abstract. Based on the exergy analysis model and the data of an ASHPWH system,exergy analysis of the system was carried out,and the way was discussed to reduce exergy loss. The exergy efficiency of the system was $43.7 \%$, and the exergy loss coefficient of the compressor was the largest in the system, accounting for $26.12 \%$.then, the exergy loss coefficient of the expansion valve, the condenser and the evaporator account for $14.15 \%, 9.82 \%$ and $6.21 \%$ respectively. The key components to improve the exergy efficiency were compressor and expansion valve, and the join control of electronic expansion valve and variable frequency compressor may be a feasible way to improve improve exergy efficiency.
\end{abstract}

\section{Introduction}

Air source heat pump water heater(ASHPWH) is efficient, energy-saving, green, and environmentally-friendly. In order to improve the performance of ASHPWH system,quite a few researchers have eneaged in researches. Guo Zhimin[1] have compared the influences of tube-in-tube condenser and plate-type condenser on the operating performance of heat pump system under standard conditions, finding that COP is improved by $20 \%$ when using plate-type condenser than tube-in-tube. Pei Gang[2] have found that instantaneous heating modes not only have higher COP than cyclic heating modes, but also have higher exergy efficiency. Zhang Taikang[3] have carried out contrastive analysis of the influences on suction-exhaust pressure and temperature,the input power, heating capacity, and performance coefficient of compressor charging the refrigerant such as R134a, R417a, and R22, which show that operational efficiency can be increased if refrigerant is chosen considering environmental conditions and final water temperature. Ming Liujiang[4] have incorporated a novel dual-fuzzy-controller to regulate the electronic expansion valve (EEV) specialized for the ASHPWH system, which obviously improves the COP of ASHPWH system. Zhang Jie[5]have carried out optimal calculation and corresponding experiments of ASHPWH system, which showed that adjusting charge volume and the openness of EEV as well as changing the length of condensing coil can enhance the COP and improve systematic stability.

Many researchers would study the energy utilization status of various systems by adopting exergy analysis method. Yi Qiujie[6] have carried out exergy analysis on SAHPM system to put forward the opinion that compressor and evaporator have large exergy loss coefficient under heating conditions, and are the critical parts for reducing systematic exergy loss. Zafer Erbay[7] have evaluated the performance of the GSHP system used in food drying by adopting traditional and modified exergy analysis method,showing that the most important component in this system is condenser, and $90 \%$ of exergy loss can be avoided in terms of design. F. Suleman[8] have researched the solar heat pump integrated system used in industrial heating by adopting energy analysis method and exergy analysis method, showing that when the exergy of the system is $75 \%$, the energy efficiency is $58 \%$, and when the exergy efficiency is $42.5 \%$, the COP of heat pump circulation is 3.54 . Y.W.Li[9] have carried out experimental research and thermodynamics analysis on the direct-expansion solar-assisted heat pump water heater of $750 \mathrm{~W}$ and $400 \mathrm{~W}$ respectively,finding that the biggest exergy loss of these two models of water heater both happen in compressor and heat collector or evaporator, and they suggested that this kind of system should be equipped with electronic-expansion valve and inverter compressor. The exergy analysis method is seldom in the research of ASHPWH system. In this article, we adopt exergy analysis method to set up the exergy analysis model of ASHPWH system and debate about the method for improving exergy efficiency, 
and hopefully provide a reference for improving the performance of ASHPWH system further.

\section{System description and experimental setup}

System description The schematic of an air source heat pump water system is shown in Fig. 1.The air source heat pump water heater model is SKF - 5.0 X/D22,the rated heating capacity is $19 \mathrm{~kW}$,the rated power is $4420 \mathrm{~W}$, the maximum input power is $6800 \mathrm{~W}$, the output water is $400 \mathrm{~L} / \mathrm{h}$ and the refrigerant is R22.The ambient temperature of the typical operating mode is $17 \square$.

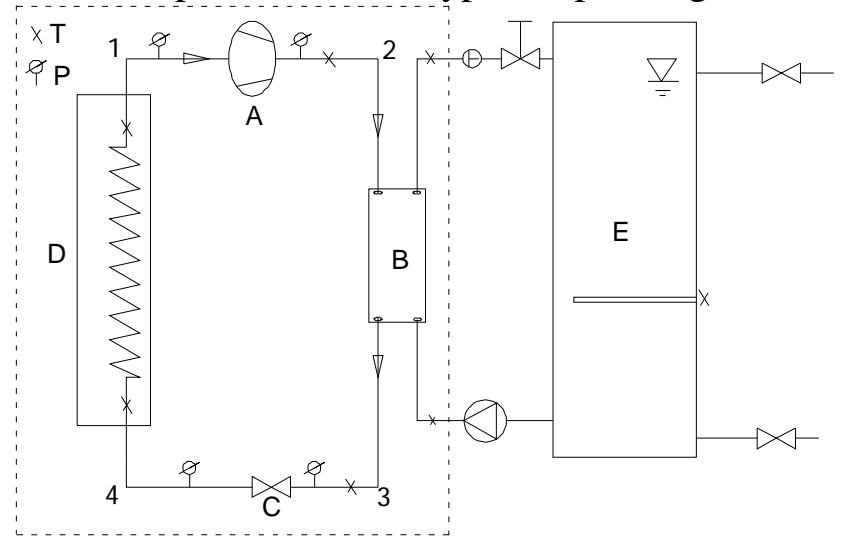

A-Compressor B-Condenser C-Expansion valve D-Evaporator E-Heat storage tank T-Temperature P-Pressure Point 1 - compressor inlet (evaporator outlet) point 2 - condenser inlet (compressor outlet) Point3-expansion valve inlet(condenser outlet) Point4-evaporator inlet(expansion valve outlet)

Fig. 1.Schematic of an air source heat pump water system.

Thermodynamic parameters of each state point The parameter of each state point is listed in Table 1. The pressure and temperature values of the points in the table can be read directly from the instrument . Enthalpy and entropy are using REFPROP software detected.The exergy of each point is calculated by the Eq. 1

$$
e_{i}=h_{i}-h_{0}-T_{0}\left(s_{i}-s_{0}\right)
$$

Table 1 The parameter of each state point

\begin{tabular}{cccccc}
\hline The test points & $\begin{array}{c}\mathrm{P} \\
(\mathrm{MPa})\end{array}$ & $\begin{array}{c}\mathrm{T} \\
(\mathrm{K})\end{array}$ & $\begin{array}{c}\mathrm{h} \\
(\mathrm{KJ} / \mathrm{Kg})\end{array}$ & $\begin{array}{c}\mathrm{s} \\
{[\mathrm{KJ} /(\mathrm{Kg} * \mathrm{~K})]}\end{array}$ & $\begin{array}{c}\mathrm{e} \\
(\mathrm{KJ} / \mathrm{Kg})\end{array}$ \\
\hline 1 & 0.64 & 281.15 & 407.89 & 1.7395 & 65.63 \\
2 & 2.425 & 367.15 & 458.12 & 1.7847 & 102.74 \\
3 & 2.425 & 328.15 & 268.82 & 1.2251 & 75.85 \\
4 & 0.64 & 281.15 & 268.82 & 1.2496 & 68.75 \\
Environment & 0.101 & 290.15 & 422.11 & 2.0147 & - \\
\hline
\end{tabular}

\section{Exergy analysis model}

In order to predict the operation performance of ASHPWH system and find the influence of exergy loss on its operation, a mathematical model has been formulated in this paper. Some physical assumptions employed for the present model are:

(1) Compression of refrigerant vapor is assumed to follow a polytropic process.

(2) Pressure drop is negligible in evaporator, condenser as well as pipes.

(3) Expansion of refrigerant liquid is considered to be isenthalpic.

According to the assumption that the actual cycle curve of ASHPWH system is simplified and exergy analysis model is established.the actual cycle curve of ASHPWH system on a lgp-h diagram is shown in Fig. 2. 


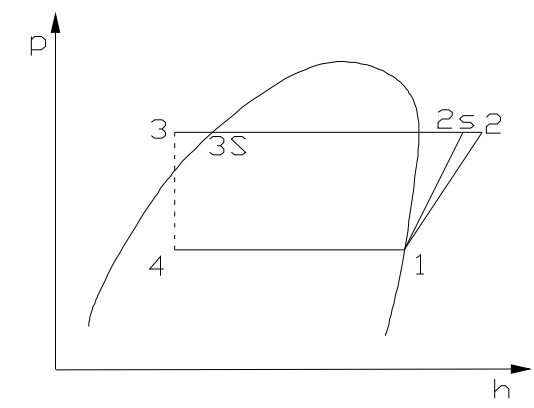

Fig. 2. The air source heat pump water heater cycle on a lgp-h diagram.

Compressor model(process 1 - 2)Since the compression of refrigerant vapor is assumed to be a polytropic process, the exergy balance equation for the compressor can be expressed as:

$$
E_{L 1}=W+E_{1}-E_{2}
$$

The exergy loss coefficient equation for the compressor can be expressed as:

$$
\xi_{1}=\frac{E_{L 1}}{W}
$$

Condenser model(process 2 - 3)The refrigerant heat transfer to the water in the tank in the process of condensation.The condenser exergy balance equation can be expressed as:

$$
E_{2}-E_{3}=E_{L 2}+\left(1-\frac{T_{0}}{T_{h}}\right) Q
$$

The exergy loss coefficient equation for the condenser can be expressed as:

$$
\xi_{2}=\frac{E_{L 2}}{W}
$$

Expansion valve model(process 4 - 5) Since the expansion of refrigerant is assumed to be isenthalpic,the expansion valve exergy balance equation is:

$$
E_{3}=E_{L 3}+E_{4}
$$

The exergy loss coefficient equation for the expansion valve can be expressed as:

$$
\xi_{3}=\frac{E_{L 3}}{W}
$$

Evaporator model (process 5 - 1)The evaporator exergy balance equation is:

$$
E_{4}=E_{L 3}+E_{1}
$$

The exergy loss coefficient equation for the evaporator can be expressed as:

$$
\xi_{4}=\frac{E_{L 4}}{W}
$$

ASHPWH system The exergy balance equation of ASHPWH system is:

$$
\xi=\frac{E_{L}}{W}=\Sigma \xi_{i}
$$

The exergy efficiency equation of ASHPWH system is: $\eta_{e}=1-\xi=1-\Sigma \xi_{i}$

\section{Calculation results and discussions}

Calculation results By calculating system total input power is $5.023 \mathrm{~kW}$.According to Table $\mathbf{1}$ of each state point parameter values and the exergy analysis model, the system's exergy efficiency is 43.7\%. The exergy loss and exergy loss coefficient of components are shown in Table 2. 
Table 2 The calculation results of Exergy loss

\begin{tabular}{cccc}
\hline Part & $\begin{array}{c}\text { Exergy loss } \\
(\mathrm{KW})\end{array}$ & $\begin{array}{c}\text { Exergy loss rate } \\
(\%)\end{array}$ & $\begin{array}{c}\text { Exergy loss coefficient } \\
(\%)\end{array}$ \\
\hline Compressor & 1.312 & 46.4 & 26.12 \\
Condenser & 0.493 & 17.4 & 9.82 \\
Expansion valve & 0.711 & 25.2 & 14.15 \\
Evaporator & 0.312 & 11 & 6.21 \\
\hline
\end{tabular}

Discussions Judging from Table 2.The exergy loss coefficient of compressor was the largest of the system ,accounting for $26.12 \%$, the exergy loss coefficient of expansion valve, the condenser and evaporator for $14.15 \%, 9.82 \%$ and $6.21 \%$ respectively. The thermal performance of various heat pump systems is shown in Table 3. Through comparison, ASHPWH system has higher exergy efficiency than other systems. In each system, compressor has the biggest exergy loss. So promoting the exergy efficiency of compressor is the feasible way to improve the exergy efficiency of each system.

Table 3 Thermal performance comparison of various heat pump system

\begin{tabular}{|c|c|c|c|c|c|}
\hline \multirow{2}{*}{ Type } & \multirow{2}{*}{$\begin{array}{c}\text { Exergy } \\
\text { efficiency of } \\
\text { system }\end{array}$} & \multicolumn{4}{|c|}{ Exergy loss coefficient } \\
\hline & & Compressor & Condenser & Expansion valve & Evaporator \\
\hline $\begin{array}{l}\text { Direct radiant floor heating system with } \\
\text { air source heat pump[10] }\end{array}$ & $30 \%$ & $24 \%$ & $13 \%$ & $5 \%$ & $11 \%$ \\
\hline $\begin{array}{l}\text { Solar assisted heat pump multi-function } \\
\text { machine system [6] }\end{array}$ & $20 \%$ & $48 \%$ & $4 \%$ & $3 \%$ & $25 \%$ \\
\hline $\begin{array}{l}\text { Groundwater source heat pump } \\
\text { system[11] }\end{array}$ & $30 \%$ & $31 \%$ & $5 \%$ & $16 \%$ & $18 \%$ \\
\hline Gas engine-driven heat pump[12] & $29.10 \%$ & - & - & - & - \\
\hline
\end{tabular}

(1) Compressor:The compressor has the biggest exergy loss, accounting for $46.4 \%$ of the system. Judging from Table 3 that the compressor of this system has the same exergy loss as other similar systems. Compressor has low adiabatic efficiency at present, which causes the great exergy loss. This problem can be solved by adopting double-stage compressor or isentropic and efficient compressor. When the pressure of compressor is huge, double-stage compressor can be adopted. It has two working stages: refrigerant enter low-stage compressor, and go through an intermediate cooling process before entering high-stage compressor. It can reduce the inlet temperature of compressor,So achieve the goal of reduce exergy loss[13].

(2) Expansion valve: The expansion valve also has great exergy loss, accounting for $14.15 \%$, and accounting for $25.1 \%$ of total exergy loss. Judging from Table 3, the exergy loss of the expansion valve of ASHPWH system has large proportion in comparison with other systems. Reducing the exergy loss of the expansion valve is improving the circulatory combination, which usually comprises the use of steam regenerative circulation.Adding a regenerator to the system. Low-temperature gaseous refrigerant will enter the regenerator after coming out of evaporator, and have heat exchange with the refrigerant in condenser before entering compressor.So the temperature of the refrigerant before throttling will get lower, thus reducing exergy loss effectively. In addition, electronic expansion valve has wider range of flow regulation than thermal expansion valve does. It can be adapted to the large variation of systematic operation conditions is the best option for ASHPWH system.

(3) Condenser and evaporator:The condenser and the evaporator have low exergy loss, accounting for $9.82 \%$ and $6.21 \%$ respectively, and accounting for $17.40 \%$ and $11 \%$ of total exergy loss respectively. Judging from Table 3 that the condenser in this system has greater exergy loss than other systems. This problem can be solved by reducing the temperature difference of heat-transfer,which can be done by adopting the screwed pipe with great heat transfer coefficient, or removing the scale and heat resistance in pipe. During the design of system, we should focus on the heat insulation of water tank or use plate-type condenser. 


\section{Conclusions}

Based on the exergy analysis model and the data of an ASHPWH system, the exergy efficiency of the system is $43.7 \%$.The exergy loss coefficient of the compressor is the largest in the system,accounting for $26.12 \%$. Otherwise the exergy loss coefficient of the expansion valve, the condenser and the evaporator account for $14.15 \%, 9.82 \%$ and $6.21 \%$ respectively.

Compared with the similar heat pump system, the exergy efficiency of the air source heat pump water heater system is higher than other systems.The largest exergy loss in the all kinds of system are compressor. The key components to improve the exergy efficiency of the system are compressor.The join control of electronic expansion valve and variable frequency compressor may be a feasible way to improve improve exergy efficiency.

\section{Acknowledgments:}

This work was financially supported by a Scientific Research Fund of Hunan Provincial Education Department(13C329), and a Scientific Research Fund of Hengyang Chengdu Science and Technology Bureau(2011KS19)

\section{Reference}

[1] GUO Zhi-min,ZHU Xing-wang,WANG Zhao-xin,Direct heat pump water heater condenser optimization experimental study[J],Fluid Machinery,2012,40(1):70-72.

[2] Pei Gang, Li Guiqiang, Ji Jie*,Comparative study of air-source heat pump water heater systems using the instantaneous heating and cyclic heating modes, Applied Thermal Engineering 31 (2011) 342-347.

[3] Zhang Tai-kang, WENG Wen-bing, YU Jing, Performance research of air-source heat pump water heater using R134a, R 417a and R22[J],Fluid Machinery,2010,38(5):72-76.

[4] Mingliu Jiang, Jingyi Wu*, Ruzhu Wang, Research on the control laws of the electronic expansion valve for an air source heat pump water heater, Building and Environment 46 (2011) 1954-1961.

[5] Zhang Jie, Zhang Liangjun, Wang Ruzhu, System optimization calculation and experimental research of air-source heat pump water heater[J], Acta Engergiae Solaris Sinica,2007,28(3)286- 289.

[6] Yi Qiu-Jie , Yang Qian-ming, Kong Xiang-qiang,Exergy analysis of solar assisted heat pump multi-function machine system[J],Gas and Heat,2008,28(10):10-12.

[7] Zafer Erbay, Arif Hepbasli, Application of conventional and advanced exergy analyses to evaluate the performance of a ground-source heat pump (GSHP) dryer used in food drying , Energy Conversion and Management 78 (2014) 499-507

[8] F. Suleman, I. Dincer, M. Agelin-Chaab , Energy and exergy analyses of an integrated solar heat pump system , Applied Thermal Engineering 73 (2014) 559 - 566

[9] Y.W. Li, R.Z. Wang, J.Y. Wu, Experimental performance analysis and optimization of a direct expansion solar-assisted heat pump water heater , Energy 32 (2007) 1361-1374

[10] Zeng Zhang-huan, Wu Jin-jing, Wei Xin-li,Experimental research and thermodynamic analysis of direct radiant floor heating system with air source heat pump[J],Acta Engergiae Solaris Sinica,2011,32 ( 8 ) : 1151-1157. 
[11] Jing You-yin, Zhang Guo-zhong, Fang Yue- lan,Exergy analysis of groundwater source heat pump system[J],Gas and Heat,2006,26 ( 5 ) : 53-57.

[12] Ma Yi - tai , Xie Ying - bai , Yang Zhao,Thermodynamic analysis of gas engine-driven heat pump[J],Journal of Thermal Science and Technology,2003,2 ( 1 ) : 1-4.

[13] Zhao Fang, Yang Qian-ming, Kong Xiang-qiang,Exergy analysis for experimental system of solar assisted heat pump multi-function machine[J],Fluid Machinery,2007,35(11):66-70. 